\title{
EFEKTIVITAS EKSTRAK TONGKOL JAGUNG (Zea mays L.) SEBAGAI DIURETIKA PADA TIKUS PUTIH JANTAN GALUR WISTAR (Rattus norvegicus)
}

\section{EFFECTIVENESS OF CORNCOB EXTRACT (Zea mays L.) AS DIURETICS ON WHITE WISTAR MALE RAT (Rattus norvegicus)}

\author{
I GUSTI AGUNG AYU KUSUMA WARDANI*• \\ *Program Studi Diploma III Farmasi Fakultas Farmasi Universitas Mahasaraswati Denpasar \\ Jalan Kamboja No 11A, Denpasar, Bali
}

\begin{abstract}
Abstrak: Diuretika adalah zat yang bekerja langsung pada ginjal dengan meningkatkan produksi urine. Diuretika dipakai pada pengobatan edema, hipertensi, dan batu ginjal. Tongkol jagung merupakan salah satu bahan alam yang belum dimanfaatkan secara maksimal untuk pengobatan, namun mengandung senyawa flavonoid yang dapat berfungsi sebagai diuretika. Tujuan penelitian ini adalah untuk mengetahui efektivitas ekstrak tongkol jagung (Zea mays L.) sebagai diuretika pada tikus putih jantan galur wistar (Rattus Norvegicus). Penelitian ini merupakan penelitian eksperimental dengan rancangan yang digunakan yaitu randomized control group post test only design, dengan menggunakan 28 ekor tikus putih jantan yang dibagi menjadi 4 kelompok perlakuan. Kelompok kontrol negatif (P1) diberikan CMC - Na, kelompok kontrol positif (P2) diberikan suspensi furosemide, sedangkan kelompok perlakuan 1 (P3) diberikan suspensi ekstrak tongkol jagung $250 \mathrm{mg} / \mathrm{KgBB}$ dan kelompok perlakuan 2 (P4) diberikan ekstrak tongkol jagung $500 \mathrm{mg} / \mathrm{KgBB}$ secara oral. Data dianalisis secara statistika menggunakan SPSS ver.16. Diketahui bahwa paling tidak terdapat perbedaan antara dua kelompok dengan nilai $\mathrm{p}<0,05$ yang didapat dari uji Kruskall Wallis, kemudian dilanjutkan dengan uji Mann-Withney untuk melihat adanya perbedaan antara tiap kelompok. Didapatkan hasil yaitu terdapat perbedaan yang signifikan antara kelompok kontrol negatif (CMC-Na) dengan kelompok kontrol positif (furosemide), ekstrak tongkol jagung dosis $250 \mathrm{mg} / \mathrm{KgBB}$ dan ekstrak tongkol jagung dosis 500 $\mathrm{mg} / \mathrm{KgBB}$ dengan nilai $\mathrm{p}<0,05$ sedangkan kelompok kontrol positif (furosemide) tidak memiliki perbedaan yang signifikan dengan kelompok ekstrak tongkol jagung $500 \mathrm{mg} / \mathrm{KgBB}$ dengan nilai $\mathrm{p}>0,05$.
\end{abstract}

Kata kunci: diuretika, tongkol jagung, urin

\begin{abstract}
Diuretics is a substance that works directly on kidneys by increasing urine production. Diuretics can be use in the treatment of edema, hypertension and calculus of kidneys. Corncob (Zea mays L.) is one of the nature material, which has not been use maximally for medication, but it contains flavonoids that have function as diuretics. This study aims to determine the effectiveness of corncob extract (Zea mays L.) as diuretics on white wistar male rat (Rattus norvegicus). This research is an experimental study with a randomized control group posttest only design, by using 28 white wistar male rat, which were divided into 4 treatment groups. Negative control group (P1) has been given CMC-Na, Positive control group (P2) ) has been given furosemide suspension, treatment group 1 (P3) has been given suspension of corncob extract $250 \mathrm{mg} / \mathrm{KgBW}$ and treatment group 2 (P4) ) has been given suspension of corncob extract $500 \mathrm{mg} / \mathrm{KgBW}$ orally. Data was analyzed using SPSS ver.16. It is known that there are at least differences between the two groups with values $p<0,05$ that obtained from Kruskall Wallis test, than continued with Mann-Withney test to see the difference between each group. The result is that there is a significant difference between the negative control group (CMC-Na) with positive control group (furosemide), corncob extract $250 \mathrm{mg} / \mathrm{KgBW}$, and corncob extract $500 \mathrm{mg} / \mathrm{KgBW}$ with values $\mathrm{p}<0,05$ while there is no significant difference between the positive control group (furosemide) with corncob extract $500 \mathrm{mg} / \mathrm{KgBW}$ with values $\mathrm{p}>0,05$.
\end{abstract}

Keyword: corncob, diuretic, urine

\section{PENDAHULUAN}

Hipertensi (tekanan darah tinggi) adalah suatu faktor resiko penting yang dapat mengarah pada terjadinya komplikasi kardiovaskular. Secara umum seseorang akan dinyatakan menderita hipertensi jika tekanan darah sistolik/diastolic > 140/90 mmHg dimana normalnya adalah 120/80 (Herwati, dkk., 2014). Hasil Riset Kesehatan Dasar (Riskesdas) Balitbangkes tahun 2013 menunjukan prevalensi hipertensi secara nasional mencapai

\footnotetext{
•email korespondensi: kusumawardani210488@gmail.com
} 
25,8\% (Tarigan, dkk., 2018). Prevalensi penderita hipertensi pada perempuan lebih tinggi, yaitu $37 \%$, sedangkan pria $28 \%$. Berdasarkan analisis univariat dari penelitian yang dilakukan oleh Arifin dkk (2016), yaitu dari 112 responden didapatkan proporsi faktor jenis kelamin terbanyak adalah pada lansia yang berjenis kelamin perempuan $(74,1 \%)$. Adapun obat yang dapat digunakan oleh penderita hipertensi yaitu obat golongan diuretik. Penggunaan obat yang berkhasiat sebagai diuretik pada penderita hipertensi dimaksudkan agar obat diuretik bekerja dengan cara membuang kelebihan air dan natrium melalui pengeluaran urine. Dengan berkurangnya air dalam darah menjadikan volume darah menurun sehingga pekerjaan jantung menjadi lebih ringan. Di Indonesia telah banyak beredar obat diuretik salah satunya yaitu Furosemide. Obat diuretik sendiri digunakan pada semua keadaan dimana dikehendaki pengeluaran air seni yang lebih banyak, yakni pada edema, hipertensi, dan batu ginjal (Tjay dan Raharja, 2007).

Jagung (Zea Mays L.) dengan familia poaceae merupakan salah satu tumbuhan yang banyak dimanfaatkan oleh masyarakat Indonesia. Adapun beberapa bagian dari tumbuhan jagung yang dapat dijadikan obat, diantaranya yaitu bunga, biji, rambut, tongkol jagung. Beberapa masyarakat menggunakan tongkol jagung sebagai pakan ternak. Namun tak banyak orang yang tahu bahwa tongkol yang mereka anggap tidak bermanfaat ternyata memiliki khasiat obat. Berdasarkan penelitian yang dilakukan oleh Dewi dan Inaratul (2016), diketahui bahwa ekstrak etanol tongkol jagung mengandung flavonoid, saponin dan polifenol. Flavonoid diketahui berkhasiat sebagai diuretik karena dapat meningkatkan volume urine dengan cara meningkatkan laju kecepatan glomerolus (Jouad, 2001). Berdasarkan latar belakang diatas maka perlu dilakukan penelitian mengenai efektivitas ekstrak tongkol jagung sebagai diuretika.

\section{METODE PENELITIAN}

Rancangan Penelitian. Jenis penelitian yang digunakan adalah penelitian eksperimental dengan menggunakan metode randomized control group post test only design.

Bahan. Bahan yang digunakan dalam penelitian ini adalah tongkol jagung (Zea mays L.) yang diperoleh dari Kelurahan Sanur, Kecamatan Denpasar Selatan, Bali. Etanol 96\%, CMC Na (Natrium Carboxymethyl Cellulosa) 0,5\%, furosemide, aquades.
Alat. Alat yang digunakan dalam penelitian ini adalah kandang metabolik, sarung tangan, masker, tempat makan dan minum hewan coba, gelas ukur, beaker glass, pipet tetes, pisau, ayakan, timbangan, disposable syringe $1 \mathrm{ml}$ dan $5 \mathrm{ml}$, kertas saring, blender, wadah penampung urine.

Populasi dan Sampel. Populasi pada penelitian ini adalah tikus putih jantan (Rattus norvegicus). Sampel penelitian yang digunakan yaitu tikus putih jantan yang memenuhi kriteria sebagai berikut:

1. Kriteria inklusi

a. Tikus putih jantan dewasa (Umur 12-15 minggu)

b. Berat badan 100-200 g

\section{Kriteria eksklusi}

Yang termasuk kriteria eksklusi dalam penelitian ini adalah tikus yang mati atau sakit selama penelitian

Pembuatan Ekstrak Tongkol Jagung. Pembuatan ekstrak dilakukan dengan metode maserasi. Pertama serbuk simplisia yang sudah ditimbang sebanyak 100 gram dimasukkan ke dalam toples kaca untuk dimaserasi. Maserasi dilakukan dengan merendam serbuk simplisia kedalam pelarut etanol 96\%. Perbandingan sebuk simplisia dan pelarut yang digunakan yaitu 1:10. Proses maserasi dilakukan selama 3 hari dengan sesekali diaduk selama 10 menit. Kemudian setelah 3 hari, dilakukan penyaringan dengan menggunakan kain saring. Selanjutnya pelarut hasil ekstraksi diuapkan menggunakan Rotary Evaporator dan dikeringkan di oven dengan suhu $40^{\circ} \mathrm{C}$ hingga dihasilkan ekstrak kering. Ekstrak kering yang dihasilkan selanjutnya digunakan dalam pengujian efek diuretik. Bobot esktrak kental yang didapat yaitu 2,7 gram.

Pembuatan Suspensi CMC Na 0,5\%. Sebanyak $0,5 \mathrm{~g}$ CMC Na dilarutkan dalam $50 \mathrm{ml}$ aquades panas dan diaduk sedikit demi sedikit hingga terbentuk mucilago kemudian ditambahkan aquades ad $100 \mathrm{~mL}$ kemudian diaduk hingga homogen.

Pembuatan Suspensi Furosemide. Menurut Drug Information Handbook (DIH), dosis penggunaan furosemide pada manusia dewasa adalah 20-80 mg. Pada penelitian ini, digunakan dosis furosemide yaitu $40 \mathrm{mg}$ dengan faktor konversi dari manusia $(70 \mathrm{~kg})$ ke tikus dengan berat 200 gram adalah 0,018. Dosis furosemide yang digunakan yaitu $0,72 \mathrm{mg} / 200 \mathrm{~g} \mathrm{BB}$ 
Ekstrak Etanol Tongkol Jagung. Ekstrak tongkol jagung dibuat menjadi dua dosis yaitu $250 \mathrm{mg} / \mathrm{kg}$ $\mathrm{BB}$ dan $500 \mathrm{mg} / \mathrm{kg}$ BB yang dilarutkan dalam suspensi CMC - Na 0,5\%. Masing - masing tikus akan diberikan 2,5 $\mathrm{ml}$ suspensi ekstrak etanol.

Perlakuan Hewan Uji. Hewan uji yang digunakan dalam penelitian ini diberi pakan dan kondisi lingkungan yang sama. Sebelum digunakan dalam penelitian, hewan uji diadaptasikan terlebih dlu selama 7 hari.

Pengukuran Volume Urine. Setelah diberi perlakuan, hewan uji dimasukkan ke dalam metabolic cage untuk ditampung urinnya. Dilakukan pengukuran urine selama 24 jam dari pemberian bahan uji pada hewan coba. Urine yang tertampung dalam wadah diambil menggunakan disposable syringe $1 \mathrm{ml}$. Selama perlakuaan hewan coba tidak diberi makan namun tetap diberi minum.Analisis Data. Data dianalisis dengan program stastistika yaitu dengan SPSS ver.16. Uji normalitas dilakukan dengan menggunakan uji Shapiro-wilk karena sampel yang digunakan dalam jumlah kecil $(<50)$. Data yang diperoleh tidak terdistribusi normal maka dilakukan uji Kruskall Wallis kemudian dilanjutkan dengan uji MannWithney.

\section{HASIL DAN PEMBAHASAN}

\section{Klasifikasi Tanaman Jagung (Zea mays $\mathbf{L}$.)}

Berdasarkan hasil determinasi tanaman pada Lembaga Ilmu pengetahuan Indonesia (LIPI) yang berlokasi di kebun raya "Eka Karya" Bali, klasifikasi tanaman Jagung (Zea mays L.) yaitu:

\begin{tabular}{|c|c|}
\hline Kingdom & : Plantae (Tumbuhan) \\
\hline Divisio & $\begin{array}{l}\text { Spermatophyta (Tumbuhan } \\
\text { menghasilkan bunga) }\end{array}$ \\
\hline Sub Divisio & $\begin{array}{l}\text { : Angiospermae } \\
\text { berbiji tertutup) }\end{array}$ \\
\hline Kelas & $\begin{array}{l}\text { : Monocotyledoneae (Tumbuhan } \\
\text { berkeping satu) }\end{array}$ \\
\hline Ordo & :Poales \\
\hline Suku & : Poaceae \\
\hline
\end{tabular}

\section{Hasil Pengujian Efek Diuretika Ekstrak Tongkol Jagung}

Pada penelitian ini hewan coba yang digunakan yaitu tikus putih (Rattus norvegicus), dimana tikus putih merupakan salah satu hewan yang umum digunakan dalam penelitian. Tikus putih memiliki beberapa sifat yang menguntungkan sebagai hewan uji penelitian diantaranya perkembangbiakan cepat sekali beranak tikus dapat menghasilkan sampai 15 ekor, selain itu tikus mempunyai ukuran lebih besar dari mencit dan mudah dipelihara. Pada penelitian digunakan tikus jantan dengan Galur Wistar, dimana hewan jantan dapat memberikan hasil penelitian yang lebih stabil karena tidak dipengaruhi adanya siklus estrus dan kehamilan (Pramesti, dkk., 2014).

Ekstrak etanol tongkol jagung digunakan dalam penelitian ini untuk mengetahui adanya efek diuretika dari tongkol jagung. Ekstrak dibuat dengan metode maserasi karena selain mudah dengan perendaman sampel tumbuhan akan terjadi pemecahan dinding dan memberan sel akibat perbedaan tekanan antara di luar dan di dalam sel (Yulianingtyas dan Kusmartono, 2016). Berdasarkan penelitian yang dilakukan oleh Ekowati dan Hanifah (2016), diketahui bahwa tongkol jagung yang diekstraksi dengan metode maserasi menggunakan etanol $96 \%$ mengandung flavonoid, saponin dan polifenol. Pelarut yang digunakan dalam proses maserasi yaitu etanol $96 \%$ dengan volume $1000 \mathrm{ml}$ dengan serbuk simplisia sebanyak 100 gram. Dari penelitian yang dilakukan oleh Yulianingtyas dan Kusmartono (2016) disebutkan semakin banyak pelarut yang digunakan maka berat flavonoid yang terekstrak semakin banyak dimana dengan banyaknya pelarut pemecahan dinding dan membran sel akibat perbedaan tekanan antara di dalam dan di luar sel berjalan lebih optimal sehingga flavonoid di sitoplasma akan semakin banyak yang terlarut kedalam pelarut (Koirewoa, dkk., 2012). Flavonoid adalah salah satu golongan fenol alam terbesar, karena mempunyai jumlah gugus hidroksil, atau suatu gula, flavonoid larut dalam pelarut polar salah satunya yaitu etanol (Yulianingtyas dan Kusmartono, 2016)

Sebelum dilakukan pengujian tikus terlebih dahulu dipuasakan selama 8 jam tanpa diberi makan agar tidak mempengaruhi efek dari ekstrak tongkol jagung yang diberikan, tetapi tetap diberi minum dengan tujuan agar kondisi elektrolit hewan uji tetap stabil (Lingga, dkk., 2014). Setelah dipuasakan selama 8 jam tikus diberi perlakuan. Perlakuan dilakukan selama 24 jam. Dilakukan pengamatan dalam 24 jam dikarenakan bahan untuk uji diuretika adalah bahan alam sehingga belum diketahui lama kerja hingga tercapai efek diuretika.

Adapun data rerata volume urine yang didapat dari penelitian ini tercantum pada tabel 1 . 
Tabel 1. Rata - Rata Volume Urine

\begin{tabular}{ccccccccc}
\hline & \multicolumn{7}{c}{$\begin{array}{c}\text { Volume urine }(\mathbf{m L}) \\
\text { Tikus ke- }\end{array}$} & $\begin{array}{c}\text { Volume rata- } \\
\text { rata (mL) }\end{array}$ \\
\cline { 2 - 9 } Kelompok Perlakuan & 1 & 2 & 3 & 4 & 5 & 6 & 7 & \\
& 1,83 & 1,30 & 0,97 & 1,89 & 0,98 & 1,10 & 1,38 & 1,35 \\
\hline CMC - Na & 3,92 & 3,86 & 4,00 & 5,01 & 5,00 & 5,43 & 3,89 & 4,44 \\
\hline Furosemide & 1,90 & 1,53 & 2,68 & 2,22 & 1,25 & 2,48 & 2,60 & 2,35 \\
\hline Ekstrak 250 $\mathbf{~ m g / K g B B}$ & 2,50 & 2,92 & 2,48 & 5,94 & 5,71 & 3,58 & 3,00 & 3,73 \\
\hline Ekstrak 500 $\mathbf{~ m g / K g B B ~}$ & & & & & & & & \\
\hline
\end{tabular}

Berdasarkan data di atas, untuk mempermudah pengamatan hasil volume urine rata - rata dapat dilihat pada Gambar 1.

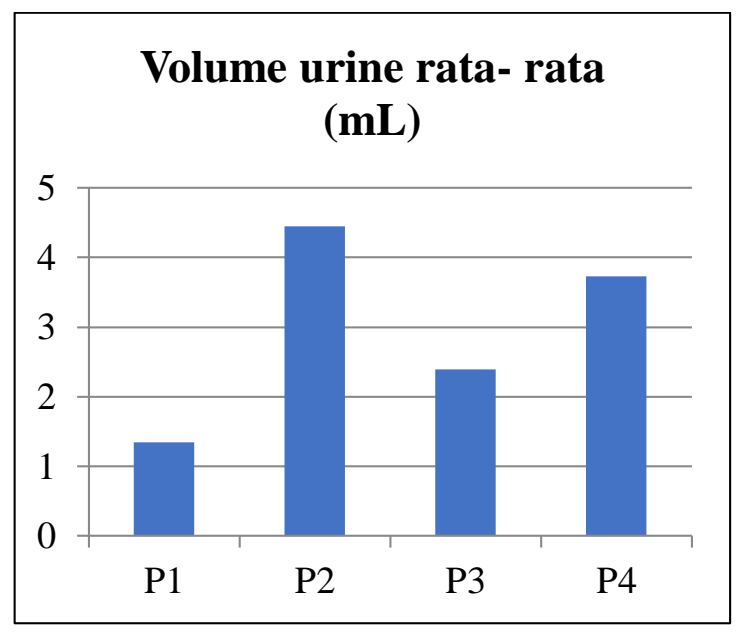

Gambar 1. Volume rata - rata urine $(\mathrm{mL})$ pada tiap kelompok perlakuan

Keterangan:

P1 : Kelompok kontrol negatif (CMC $-\mathrm{Na})$

P2 : kelompok kontrol positif (furosemide)

P3 : kelompok perlakuan ekstrak tongkol jagung $250 \mathrm{mg} / \mathrm{KgBB}$

P4 : kelompok perlakuan ekstrak tongkol jagung $500 \mathrm{mg} / \mathrm{KgBB}$

Data volume urine yang diperoleh di analisis menggunakan uji statistik dengan SPSS ver.16 untuk mengetahui normalitas dan homogenitas dari data yang didapat. Uji normalitas dilakukan dengan uji Shapiro - Wilk karena subyek yang digunakan $<50$. Apabila dari hasil analisis diperoleh $\mathrm{p}>0,05$ maka dapat dikatakan data tersebut terdistribusi normal. Berikut merupakan hasil analisis stastistik normalitas dari data yang diperoleh:

Tabel 2. Hasil Uji Normalitas Data Volume Urine

\begin{tabular}{ccc}
\hline No & Kelompok Perlakuan & Nilai P \\
\hline 1 & CMC- Na & 0,191 \\
\hline 2 & Furosemide & 0,036 \\
\hline 3 & $\begin{array}{c}\text { Ekstrak tongkol jagung } \\
250 \mathrm{mg} / \mathrm{KgBB}\end{array}$ & 0,456 \\
\hline \multirow{2}{*}{4} & $\begin{array}{c}\text { Ekstrak tongkol jagung } \\
500 \mathrm{mg} / \mathrm{KgBB}\end{array}$ & 0,035 \\
& & \\
\hline
\end{tabular}

Dari hasil analisis statistik dapat dinyatakan bahwa data tersebut tidak terdistribusi normal karena ada nilap $\mathrm{P}<0,05$ karena data tidak terdistribusi normal maka tidak dilakukan uji homogenitas. Selanjutnya data dianalisis dengan uji non parametrik yaitu Kruskall Wallis. Hasil dapat dilihat pada tabel 3.

Tabel 3. Hasil Uji Kruskall Wallis Volume Urine

\begin{tabular}{|c|c|c|c|}
\hline $\begin{array}{l}\text { Kelompok } \\
\text { perlakuan }\end{array}$ & $\mathbf{n}$ & $\begin{array}{l}\text { Volume urine } \\
\text { Median } \\
(\mathbf{m i n}-\mathbf{m a x})\end{array}$ & Nilai $\mathbf{p}$ \\
\hline $\mathrm{CMC}-\mathrm{Na}$ & 7 & $1,30(0,97-1,89)$ & \multirow{4}{*}{$<0.001$} \\
\hline Furosemide & 7 & $4,00(3,86-5,43)$ & \\
\hline $\begin{array}{c}\text { Ekstrak tongkol } \\
\text { jagung } 250 \\
\text { mg/KgBB }\end{array}$ & 7 & $2,22(1,25-2,68)$ & \\
\hline $\begin{array}{c}\text { Ekstrak tongkol } \\
\text { jagung } 500 \\
\text { mg/KgBB }\end{array}$ & 7 & $3,00(2,48-5,94)$ & \\
\hline
\end{tabular}

Pada uji kruskall wallis didapatkan nilai $\mathrm{P}=0,001(\mathrm{P}<0,05)$ artinya paling tidak terdapat perbedaan antara dua kelompok. Selanjutnya dilakukan pengujian dengan uji Mann-Withney.

Tabel 4. Hasil Uji Mann Withney Data Volume Urine

\begin{tabular}{cccccc}
\hline \multirow{2}{*}{ No } & $\begin{array}{c}\text { Kelompok } \\
\text { Perlakuan }\end{array}$ & Kelompok Pembanding & Median $(\mathbf{m i n}-\mathbf{m a x})$ & Nilai P & Keterangan \\
\hline \multirow{2}{*}{1} & \multirow{2}{*}{$\mathrm{CMC}-\mathrm{Na}$} & Furosemide & $4,00(3,86-5,43)$ & 0,002 & Ada perbedaan \\
\cline { 3 - 6 } & & Ekstrak $250 \mathrm{mg} / \mathrm{KgBB}$ & $2,22(1,25-2,68)$ & 0,018 & Ada perbedaan \\
\cline { 3 - 6 } & & Ekstrak $500 \mathrm{mg} / \mathrm{KgBB}$ & $3,00(2,48-5,94)$ & 0,002 & Ada perbedaan \\
\hline
\end{tabular}




\begin{tabular}{|c|c|c|c|c|c|}
\hline No & $\begin{array}{l}\text { Kelompok } \\
\text { Perlakuan } \\
\end{array}$ & Kelompok Pembanding & Median (min - max) & Nilai $\mathbf{P}$ & Keterangan \\
\hline \multirow{3}{*}{2} & \multirow{3}{*}{ Furosemide } & $\mathrm{CMC}-\mathrm{Na}$ & $1,30(0,97-1,89)$ & 0,002 & Ada perbedaan \\
\hline & & Ekstrak $250 \mathrm{mg} / \mathrm{KgBB}$ & $2,22(1,25-2,68)$ & 0,002 & Ada perbedaan \\
\hline & & Ekstrak 500 mg/KgBB & $3,00(2,48-5,94)$ & 0,180 & Tidak ada perbedaan \\
\hline \multirow{3}{*}{3} & \multirow{3}{*}{$\begin{array}{l}\text { Ekstrak } 250 \\
\mathrm{mg} / \mathrm{KgBB}\end{array}$} & CMC-Na & $1,30(0,97-1,89)$ & 0,018 & Ada perbedaan \\
\hline & & Furosemide & $4,00(3,86-5,43)$ & 0,002 & Ada perbedaan \\
\hline & & Ekstrak 500 mg/KgBB & $3,00(2,48-5,94)$ & 0,011 & Ada perbedaan \\
\hline \multirow{3}{*}{4} & \multirow{3}{*}{$\begin{array}{l}\text { Ekstrak } 500 \\
\mathrm{mg} / \mathrm{KgBB}\end{array}$} & CMC-Na & $1,30(0,97-1,89)$ & 0,002 & Ada perbedaan \\
\hline & & Furosemide & $4,00(3,86-5,43)$ & 0,180 & Tidak ada perbedaan \\
\hline & & Ekstrak $250 \mathrm{mg} / \mathrm{KgBB}$ & $2,22(1,25-2,68)$ & 0,011 & Ada perbedaan \\
\hline
\end{tabular}

Berdasarkan analisis dengan uji MannWithney pada tabel 4 terdapat perbedaan yang signifikan antara kelompok CMC-Na dengan semua kelompok lainnya, hal tersebut dikarenakan tidak ada zat-zat yang dapat menimbulkan efek diuretika pada kelompok CMC-Na sehingga sekresi urine yang dikeluarkan sedikit. Adanya peningkatan urin pada kelompok perlakuan kemungkinan disebabkan karena adanya kandungan flavonoid pada tongkol jagung. Menurut Jouad (2001) flavonoid dapat meningkatkan volume urine dengan cara meningkatkan laju kecepatan glomerolus. Selain itu flavonoid dapat menghambat reabsorbsi $\mathrm{Na}^{+}$ dan $\mathrm{Cl}^{-}$sehingga menyebabkan peningkatan $\mathrm{Na}^{+}$ dan air dalam tubulus. Dengan demikian terjadi peningkatan volume air dalam tubulus dan terjadi peningkatan volume urine (Nurihardiyanti, dkk., 2015).

Pada kelompok furosemide dan kelompok perlakuan $250 \mathrm{mg} / \mathrm{KgBB}$ diperoleh nilai signifikan 0,002 , hal ini menunjukkan bahwa terdapat perbedaan yang signifikan antara kedua kelompok. Hal ini disebabkan furosemide merupakan obat golongan diuretik kuat. Furosemide bekerja di ansa henle terutama pada bagian tebal asendens, obat ini bekerja dengan cara menghambat ko-transport $\mathrm{Na}^{+}$ dan $\mathrm{Cl}^{-}$dan menghambat reabsorbsi air. Selain itu diuretik kuat ini juga meningkatkan ekskresi kalium, kalsium dan magnesium (Tjay dan Raharja, 2007).

Pada kelompok furosemide dengan ekstrak $500 \mathrm{mg} / \mathrm{KgBB}$ diperoleh nilai $\mathrm{P}>0,05$ hal ini menunjukkan tidak ada perbedaan signifikan volume urine paa kedua kelompok.

\section{KESIMPULAN}

Berdasarkan penelitian yang telah dilakukan dapat dapat disimpulkan bahwa ekstrak etanol tongkol jagung (Zea mays L.) dosis 500 $\mathrm{mg} / \mathrm{KgBB}$ efektif sebagai diuretika pada tikus putih jantan Galur Wistar (Rattus norvegicus).

\section{DAFTAR PUSTAKA}

Arifin, M.J.B.M., Weta, I.W., Ratnawati, N.L.K.A., 2016. Faktor - Faktor yang Berhubungan dengan Kejadian Hipertensi pada Kelompok Lanjut Usia di Wilayah Kerja UPT Puskesmas Petang I Kabupaten Badung Tahun 2016. E-Jurnal Medika, Vol 5 No.7, Juli 2016

Ekowati, D., Hanifah, I.R., 2016. Potensi Tongkol Jagung (Zea mays L.) sebagai Sunscreen dalam Sediaan Hand Body Lotion. Jurnal Ilmiah Manuntung, 2(2), 198-207,2016

Herwati dan Sartika, W. 2014. Terkontrolnya Tekanan Darah Penderita Hipertensi Berdasarkan Pola Diet dan Kebiasaan Olahraga di Padang Tahun 2011. Jurnal Kesehatan Masyarakat, Vol.8, No.1

Jouad H, Dubois MAL, Lyoussi B, Edduks M, 2001, Effects of The Flavonoids Extract from Spregularia pupurea Pers, On Arterial Blood Pressure and Renal Function in Normal and Hypertensive Rats. Journal of Ethno pharmacology. Vol. 76: 159-163

Koirewoa,Y.A., Fatmawali, W.I., Wiyono., 2012. Isolasi dan Identifikasi Senyawa Flavonoid dalam Daun Beluntas (Pluchea indica L.). Laporan Penelitian. FMIPA UNSRAT. Manado

Lingga, I.S., Citraningtyas,G., Lolo,W.A., 2014. Uji Efek Ekstrak Etanol Patikan Kebo (Euphorbia hirta Linn.) sebagai Diuretika pada Tikus Putih Jantan Galur Wistar (Rattus noevegicus $s p$.)

Nurihardiyanti, Yuliet, Ihwan. 2015. Aktivitas Diuretik Kombinasi Ekstrak Biji Pepaya (Carica papaya L.) dan Biji Salak (Salacca zalacca varietas zalacca (Graert.) Voss) pada Tikus Putih Jantan Galur Wistar (Rattus 
norvegicus L.). GALENIKA Journal of Pharmacy Vol.1 (2): 105 - 112 october 2015

Pramesti, R., Widyastuti, N., 2014. Pengaruh Pemberian Jus dan Ubi Jalar (Ipomoea batatas (L.) Lam) terhadap Kadar Kolesterol LDL Tikus Wistar Jantan (Rattus noevegicus L.) yang Diberi Pakan Tinggi Lemak. Journal of Nutrition College, Vol. 3 No. 4, 2014

Tarigan, A.R., Lubis, Z., Syarifah. 2018. Pengaruh Pengetahuan, Sikap dan Dukungan Keluarga Terhadap Diet Hipertensi di Desa Hulu Kecamatan Pancur Batu Tahun 2016. Jurnal Kesehatan Vol. 11 No.1 Tahun 2018
Tjay, Tan Hoan dan Kirana Rahardja. 2007. ObatObat Penting Khasiat, Penggunaan dan EfekEfek Sampingnya, Edisi Keenam, 262, 269 271, PT. Elex Media Komputindo. Jakarta

Trihardjana. 2007. Kajian Potensi Diuretika dari Beberapa Jenis Tanaman di Sekitar Rumah. Jurnal Biologi FMIPA UNY

Yulianingtyas, A., Kusmartono B., 2016. Optimasi Volume Pelarut dan Waktu Maserasi Pengambilan Flavonoid Daun Belimbing Wuluh (Averrhoa bilimbi L.). Jurnal Teknik Kimia Vol.10, No.2, April 2016. 